\title{
Relationship between the Indian summer monsoon and the large-scale circulation variability over the Mediterranean
}

\author{
Despoina Rizou $^{\text {a,* }}$, Helena A. Flocas ${ }^{a}$, Panos Athanasiadis ${ }^{b}$, Aristides Bartzokas ${ }^{c}$ \\ a Division of Environmental Physics and Meteorology, Department of Physics, National and Kapodistrian University of Athens, University Campus, Building Phys.-5, \\ 15784 Athens, Greece \\ ${ }^{\mathrm{b}}$ CMCC-Centro Euro-Mediterraneo sui Cambiamenti Climatici, Viale Aldo Moro, 44 I-40127 Bologna, Italy \\ c Laboratory of Meteorology, Department of Physics, University of Ioannina, 45110 Ioannina, Greece
}

\section{A R T I C L E I N F O}

\section{Article history:}

Received 27 May 2014

Received in revised form 11 July 2014

Accepted 14 July 2014

Available online 23 July 2014

\section{Keywords:}

Indian summer monsoon

Atmospheric circulation

Mediterranean

Rossby waves

Jet stream

Etesians

\begin{abstract}
A B S T R A C T
In this study the impact of the Indian summer monsoon on the large scale variability of the atmospheric circulation over the Mediterranean is investigated on an inter-annual time scale. Composite and correlation analysis results are presented, outlining different circulation patterns in the upper and lower troposphere for strong and weak monsoon years respectively. For this purpose ERA-40 Reanalysis monthly mean data at various isobaric levels together with the standardized All India Rainfall Index for boreal summer (June-July-August-September) of a 44year period were employed. During strong monsoon years many atmospheric circulation systems appear strengthened over Eurasia, resembling a well-organized Rossby wave train over the area. In the upper troposphere a meridional shift of the jet streams over the examined area was also identified during extreme monsoon years. On the other hand, in the lower troposphere enhanced northerlies (Etesians) appear to dominate over Eastern Mediterranean along with intensified subsidence during strong monsoon years.
\end{abstract}

(C) 2014 Elsevier B.V. All rights reserved.

\section{Introduction}

The Indian summer monsoon (ISM) is nowadays considered to be an integral part of the global climate system. Previous studies have shown that the ISM is affected by climatic conditions in other parts of the world and many of them focused on the influence of mid-latitude synoptic disturbance on the ISM (Ding and Sikka, 2005; Fujinami and Yasunari, 2004; Kripalani and Kulkarni, 1997). For instance, Ding and Wang (2007) studied the interaction between the mid-latitude flow and the ISM and proposed that the eastward and southward

\footnotetext{
* Corresponding author at: Division of Environmental Physics and Meteorology, Department of Physics, University of Athens, University Campus, Build Phys V, 15784 Athens, Greece. Tel.: + 30 2107276850; fax: +302107295281.

E-mail addresses: desrizou@phys.uoa.gr (D. Rizou), efloca@phys.uoa.gr (H.A. Flocas), panos.athanasiadis@cmcc.it (P. Athanasiadis), abartzok@uoi.gr (A. Bartzokas).
}

propagation of the wave train originating from the northeastern Atlantic contributes to the intra-seasonal variability of the ISM. Mediterranean Sea as well seems to have an influence on the mid-latitude circulation and the monsoon system; the baroclinic structure associated with eastern Mediterranean sea surface temperature (SST) anomalies is found that it could initiate a global atmospheric teleconnection during summerautumn period (Fontaine et al., 2011; García-Serrano et al., 2013).

On the other hand, diabatic heating associated with deep convection over India can in turn affect the mid-latitude flow through the excitation of Rossby wave trains. As noted by previous studies, the ISM convective variability can have a planetary-scale impact on an intra-seasonal as well as on an inter-annual time scale. Ding and Wang (2005, 2007) documented a summer-time circumglobal teleconnection pattern (CGT) associated with ISM that induces rainfall and surface air temperature anomalies around the Northern Hemisphere, linking regional climate variations along its path. Well-known 
regional teleconnection patterns, like the ISM-East Asian summer monsoon (EASM) and the East Asia-North America teleconnections, are considered as the regional component of the CGT. Lin (2009) showed that the ISM convective activity is responsible for a global pattern that expands in both hemispheres and is determined by the mean background flow and the relative position of the heating anomaly and the upper easterly jet over the monsoon region.

It has been also found that ISM can influence the climate to its east in the middle latitude downstream regions, i.e. the East Asia-North Pacific (Ding and Wang, 2005; Kripalani and Singh, 1993; Kripalani and Kulkarni, 1997, 2001; Wang et al., 2001; Wu et al., 2006, 2009; Zhao et al., 2009) as well as to its west mid-latitude, upstream regions. Rodwell and Hoskins (1996, 2001) studied the impact of the ISM on the weather conditions in the North African and eastern Mediterranean region. Using numerical simulation, they showed that the strong diabatic heating associated with the rainfall in the ISM region induces a Gill-type Rossby wave response to the west of the monsoon region, which interacting with the southern flank of the midlatitude westerlies produces a region of adiabatic descent in the North African and eastern Mediterranean (EM) regions. The result of this intense atmospheric heating is a large and steady descent of the isentropes from the North Atlantic to the ISM region. This tilt of the summer isentropes has a profound effect on the Mediterranean summer aridity (Eshel, 2002). Ziv et al. (2004) proposed that the two dynamic factors governing the EM during summer, the Etesian winds and the persistent subsidence over central and eastern Mediterranean, are linked to the ISM. The Etesians, persistent northerly winds which blow over the Aegean Sea during summer (Metaxas and Bartzokas, 1994), are considered to play an intermediate role in the connection between two major monsoon systems, the ISM and the African monsoon (Raicich et al., 2003; Paz et al., 2008). Tyrlis et al. (2013) examined the seasonal evolution of synchronicity of the northerly flow and the upper level subsidence over the Mediterranean and the convective activity across the distinctive subsystems of the Asian summer monsoon and investigated the dynamics leading to the observed summer circulation over the EM.

In this frame, the aim of the present study is to investigate on a climatological basis the influence of the ISM on the upper and low level atmospheric circulation over the greater Mediterranean region on an inter-annual scale, focusing on the teleconnection patterns between large scale circulations in strong versus weak monsoon years. On this new basis, the relationship between the ISM and the wind regime of EM during summer is further examined.

\section{Data and methodology}

The dataset used in this work is the monthly mean ERA40 Reanalysis Data of the European Center for MediumRange Weather Forecast (ECMWF; Uppala et al., 2005), on a $2.5^{\circ} \times 2.5^{\circ}$ grid and at standard pressure levels from $1000 \mathrm{hPa}$ to $300 \mathrm{hPa}$. Geopotential height, horizontal wind components data and several dynamic and thermodynamic parameters, covering boreal summers from 1958 to 2001, were employed. This dataset used has the longest data period for all variables of interest. In this study, summer refers to the peak ISM season, namely June, July, August, and September (JJAS). Additionally, monthly means of daily mean values of potential temperature in several pressure levels were used, from the reanalysis product of the National Center for Environmental Prediction- National Center for Atmospheric Research (NCEP-NCAR) for 1958-2001 (Kalnay et al., 1996).

The All India Rainfall Index (AIRI) by Parthasarathy et al. $(1994,1995)$ was used to select the extreme ISM years. AIRI is defined as the area-weighted average of rainfall observed at well-distributed rain-gauge stations all over India and is the most widely used measure of the intensity of the planetary scale monsoon over India (Wang and Fan, 1999). Strong (weak) ISM years are defined as years when the magnitude of seasonal (JJAS) mean AIRI is greater than +0.8 (less than - 0.8) standard deviation (Ding et al., 2011). As a result, ten strong ISM years $(1958,1961,1964,1970,1971,1975,1978$, $1983,1988,1994)$ and ten weak ISM years $(1965,1966,1968$, $1972,1974,1979,1982,1986,1987,2001)$ were derived for the 44-year examined period.

Seasonal (JJAS) mean anomalies of the above mentioned data were calculated as the seasonal deviations from the climatological seasonal means for the period 1958-2001, separately for strong and weak ISM years. Additionally, correlation maps were constructed between the gridded monthly data and the AIRI. Statistical significance for both correlation and composite anomaly maps was calculated using a two-sided Student's $t$ test.

\section{ISM and upper level circulation}

Fig. 1 presents the JJAS climatology of $500 \mathrm{hPa}$ geopotential height (Z500) and composite pattern results of the difference in Z500 between strong and weak ISM years over the Northern Hemisphere. In Fig. 1a we focus on the troughs over the eastern coast of North America and the EM, the ridge over northern Europe and the one over central Asia.

On the other hand, in Fig. 1b it can be seen that when ISM strengthens the $\mathrm{Z} 500$ increases in the ridge location over northern Europe and central Asia and decreases in the troughs over North America and EM. More specifically, the spatial pattern in the figure shows that an intensifying ISM is accompanied by strong positive anomalies centered over central and northern Europe with the central and western Mediterranean lying at the southern margin of this anomaly pattern. An area of negative anomalies is apparent over the North Atlantic and southern Greenland, presenting its highest values over the Arctic Ocean. The central Mediterranean is dominated by significant large-scale positive anomaly whereas the EM is influenced by significant negative anomalies. The presence of an anomaly trough over eastern Mediterranean, extending from north-western Russia to the south-west, may contribute to a transfer of cool air masses above the area which can substantially reinforce the low pressure system on the surface (see Fig. 7; Arseni-Papadimitriou et al., 1988). Strong positive anomalies are also found over the East Asian summer monsoon (EASM) region with maximum anomaly centers anchored over eastern Asia coast, extending from the Sea of Okhotsk to Japan and East China Sea.

This pattern also appears at $300 \mathrm{hPa}$ (not shown) with more pronounced positive anomalies over central and northern Europe, western Mediterranean, central and north-eastern Asia and with weaker negative anomalies over Greenland 
Z500 climatology (JJAS, 1958-2004)

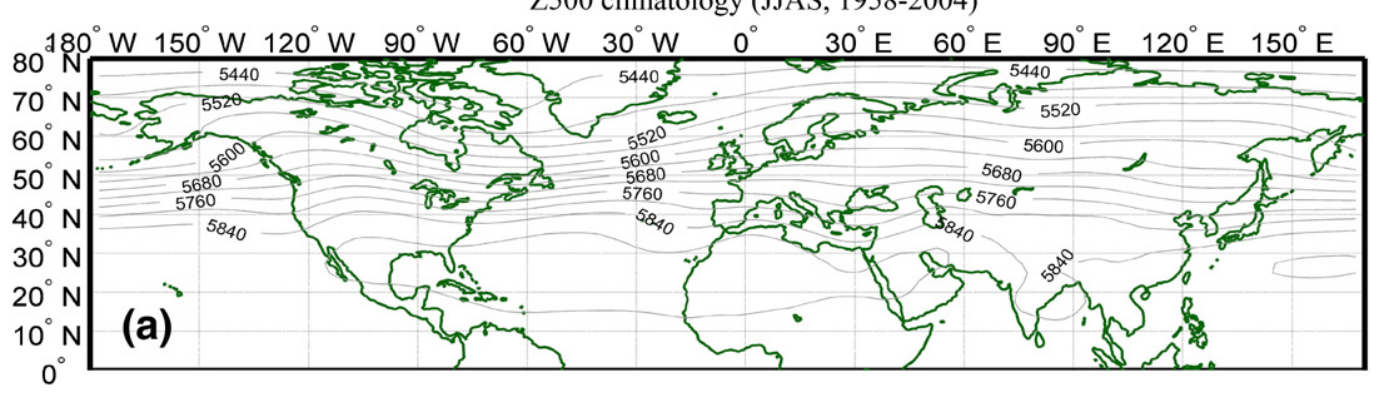

Z500 strong-weak differences

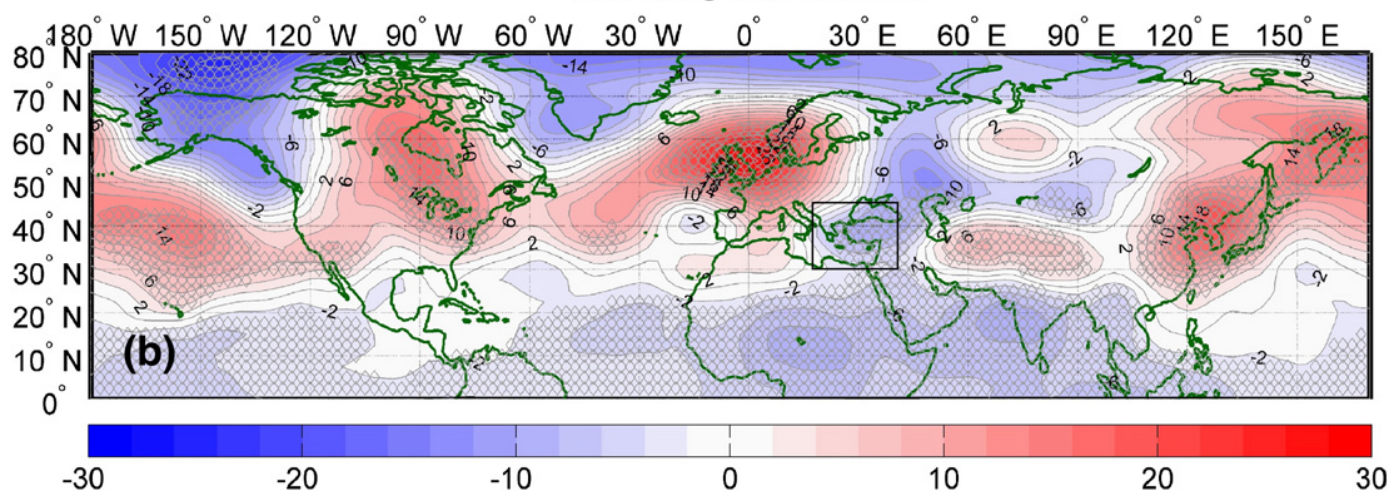

Fig. 1. (a) 1958-2001 climatology of JJAS geopotential height (contour interval of 40 gpm) at 500 hPa (Z500) and (b) difference in Z500 between strong and weak ISM years (colored contours with interval of $2 \mathrm{gpm}$ ). Grid points with anomalies that are statistically significant at $90 \%$ confidence level are denoted with diamond symbols. The EM region is denoted inside the frame $\left(30^{\circ}-45^{\circ} \mathrm{N}, 17^{\circ}-40^{\circ} \mathrm{E}\right)$.

and EM. In general, the amplitude of the geopotential height anomalies seems to increase with height. The configuration evident in both composite patterns of geopotential height in the upper troposphere depicts an eastward and equatorward wave train, with alternating troughs and ridges over Europe and Asia, which results in an undulating path for the subtropical jet. Thus, a strong ISM seems to be accompanied by an adjustment of the large-scale circulation systems that favors a stronger wave train pattern across Eurasia, Pacific and North America. This summer wave train suggests a linkage between the climate anomalies over Europe, Asia and North America. Similar relationship between the climate over West Asia, EM and the North Atlantic has been identified before, mostly over winter time (Paz et al., 2003; Tourre and Paz, 2004; Paz et al., 2008). The weather regime predominating over central Europe is widely known as blocking (resembles an "omega wave"), which causes heat and drought in western Europe by isolating the northern part of it from Atlantic influence (Cassou et al., 2005; El Kenawy et al., 2012).

The strong and weak composite anomalies of the zonal wind component at $300 \mathrm{hPa}$ are shown in Fig. 2. The examination of the weak composite (Fig. 2b) reveals a meridional shift of the subtropical jet (STJ) in the central Asia region equatorward, as compared with its climatological mean position (Rizou et al., 2012) as well as a weakening of the STJ over the central Asia and of the tropical easterly jet (TEJ) intensity over the Thar desert, in northern Indo-Pakistan region. Conversely, the phases of the zonal wind anomaly in the strong ISM years (Fig. 2a) are opposite to those in the weak ISM years. Fig. 2a shows that an intensification of the ISM is accompanied by an increase of the westerly wind component over the middle latitudes from EM region to central Asia and at the same time by a strengthening of the low latitude easterlies from eastern coast of Africa to Indo-Pakistan region. Statistically significant linear correlation of 0.45 at 0.05 significance level is found between areaaveraged zonal wind anomalies over the areas where STJ and TEJ present significant variability, i.e. $30^{\circ}-50^{\circ} \mathrm{N}, 30^{\circ}-80^{\circ} \mathrm{E}$ and $10^{\circ}-25^{\circ} \mathrm{N}$, and $30^{\circ}-80^{\circ} \mathrm{E}$ respectively. The correlation coefficient between the zonal wind anomalies at $200 \mathrm{hPa}$ was found slightly intensified (0.5). Pattanaik and Satyan (2000) found a significant correlation between the TEJ intensity and the ISM rainfall on an interannual time scale. On the other hand, intraseasonal meridional displacements of the two jets, southward for the STJ and poleward for the TEJ, were found to be closely related to break conditions of the ISM (Ramaswamy, 1962). The enhanced central Asian high (Fig. 1b), which links the circulation in the middle latitudes with that of the tropics, seems to determine the strength of the middle and lower latitude winds and thus the position of the jets. Importantly, the STJ appears to shift to the north of its mean position extending further to the west over EM with anomalously strengthened (weakened) intensity during the strong (weak) ISM years over the area. Such a STJ shift to the north can provide favorable conditions for the westward propagating Rossby wave, which is induced by the ISM heating (Lin et al., 2007; Lin, 2009). The aforementioned STJ shift is also evident at $300 \mathrm{hPa}$ relative vorticity anomaly composite for the strong ISM years (not shown), where an anomalous positive vorticity is located poleward of the anomalous westerly zonal wind. It is well known that the position of the STJ is prominent for the 

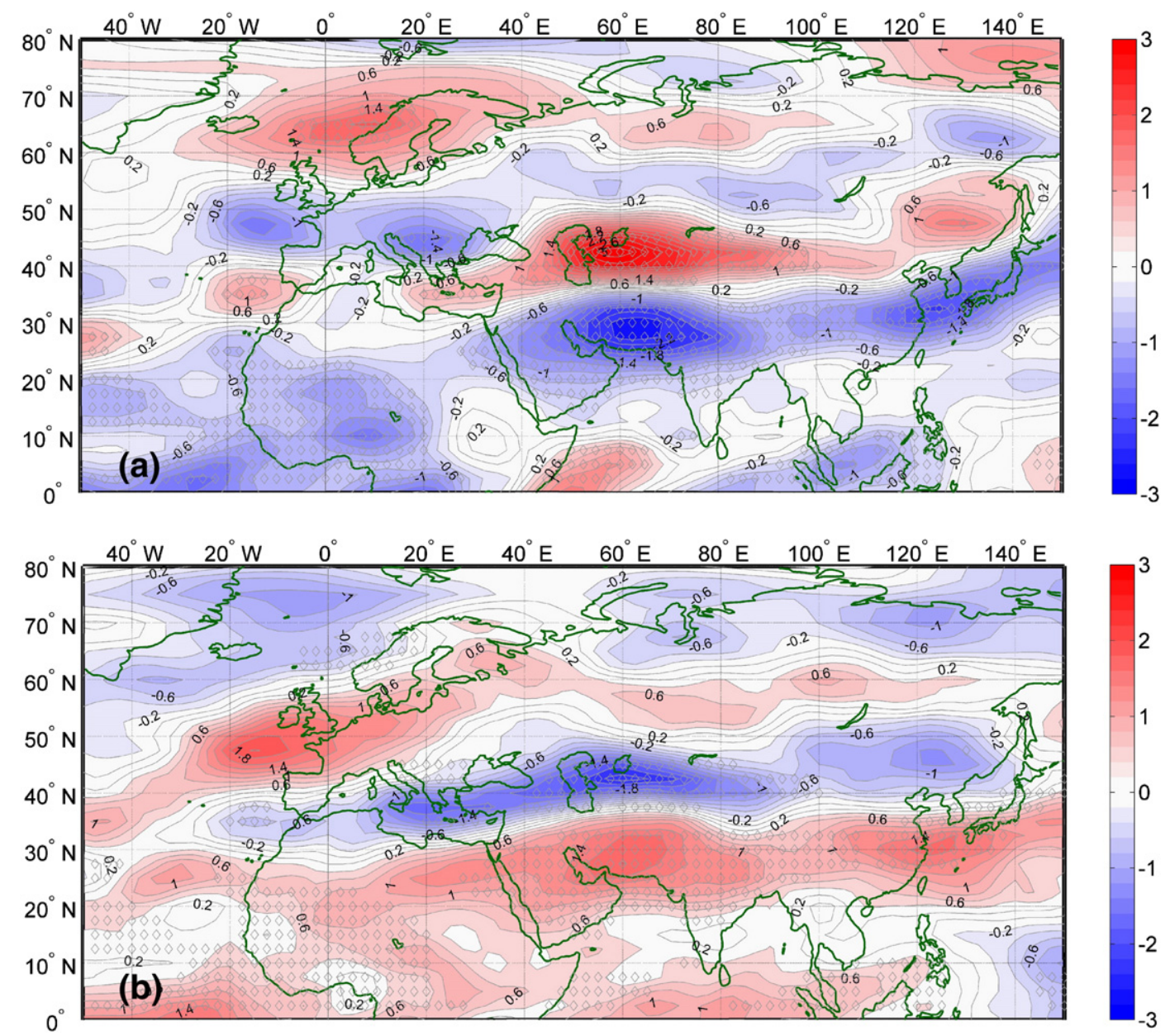

Fig. 2. Seasonal (JJAS) mean anomalies of zonal wind (coloured contours) at 300 hPa during (a) strong ISM years and (b) weak ISM years, from 44-year (1958-2001) climatology. Diamond symbols indicate statistical significance at $90 \%$ confidence level. Contour interval is $0.2 \mathrm{~m} \mathrm{~s}^{-1}$.

development of the monsoon circulation cell. As long as the STJ lies on the southern side of the Tibetan Plateau at about $30^{\circ} \mathrm{N}$, it inhibits the development of summer monsoon. As the STJ slides to the north of Himalayas and Tibet at about $40^{\circ} \mathrm{N}$ and reforms over central Asia during the summer months, the summer monsoon cell finally develops (Ramaswamy, 1962; Pai and Rajeevan, 2007; Yin, 1949). This is especially important for climatic variability in the EM, since during summer the intensity and position of the STJ over the Mediterranean are key parameters for the climate variability over the region regarding heat wave events and precipitation (Baldi et al., 2006; Brikas et al., 2006; Gaetani et al., 2011; Prezerakos and Flocas, 2002).

The corresponding seasonal anomalies in the $300 \mathrm{hPa}$ meridional wind are displayed in Fig. 3. It is evident that the meridional wind anomalies in the strong ISM years are of significant magnitude over a large region, extending to the entire mid-latitude band, whereas in the weak ISM years the anomalies are much weaker and of opposite phase. Furthermore, for the strong ISM years (Fig. 3a) the meridional wind anomalies depict a well-organized Rossby wave train of alternating southerlies and northerlies, originating from northeastern Atlantic, propagating in mid-latitudes over the whole
Northern Hemisphere and expanding to subpolar and polar latitudes over Europe, east Asia, the Pacific Ocean and northwestern America. The anomalies become more intense over Eurasia continent and the wave train propagates in a concave configuration as seen from the equator. On the other hand, during weak ISM years, the $300 \mathrm{hPa}$ meridional wind anomalies over Eurasia resemble a wave train organized by weaker anomalies confined only in the area of eastern Asia.

It is interesting to note that the wave train propagation along the above region coincides with the position of the subtropical jet in the area (see Fig. 2a). In fact, Fig. 3a reveals an anomaly pattern that is meridionally confined to the vicinity of the jets with anomalies that are zonally oriented, while the pattern in Fig. 3b is more abstract with anomalies with no specific orientation. The importance of the upper-level tropospheric jets as waveguides for the observed low-frequency waves has been stressed by previous studies (e.g. Branstator, 2002; Hoskins and Ambrizzi, 1993). According to the linear wave theory applied in these studies the waveguide action of the jet has the potential to enhance the longitudinal extent of low-frequency disturbances, since they are meridionally confined and their energy propagates further before being dissipated. According to Branstator (2002), disturbances in 

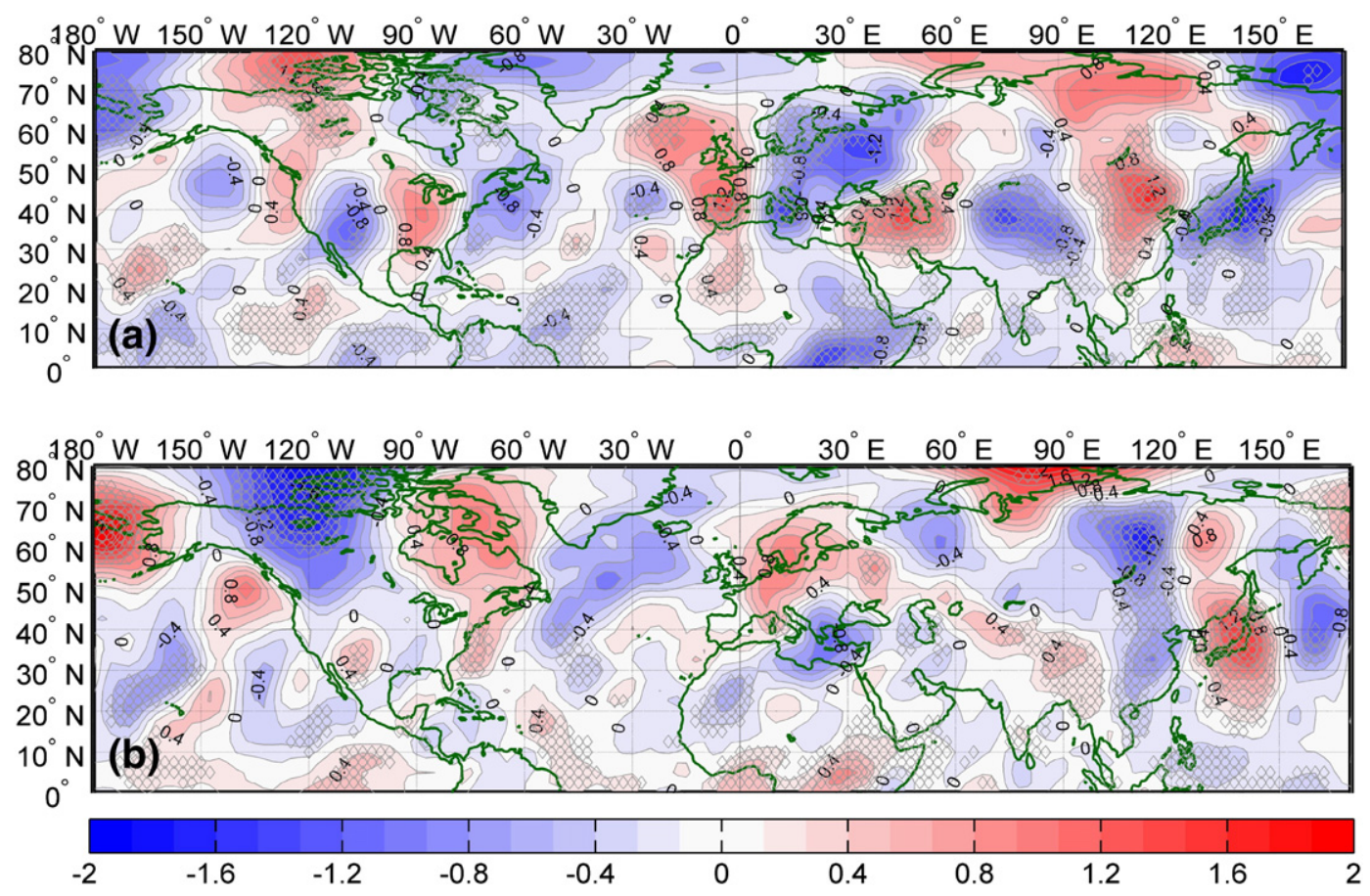

Fig. 3. Seasonal (JJAS) meridional wind component anomalies (coloured contours) at 300 hPa during (a) strong ISM years and (b) weak ISM years, from 44 -year (1958-2001) climatology. Diamond symbols indicate statistical significance at $90 \%$ confidence level. Contour interval is $0.2 \mathrm{~m} \mathrm{~s}{ }^{-1}$.

the vicinity of the mean jets lead to covariability between widely separated points, allowing the information about the disturbance to transmit rapidly and effectively throughout the domain and thus enabling the establishment of a teleconnection between the remote points of interest. In our case, the role of the subtropical jet may play a crucial role in the enhancement of the teleconnection between the ISM and the EM region.

In order to confirm the results from the composite analysis, correlation maps were constructed, depicting the linear, temporal correlation between the monthly AIRI values for summer months during period 1958-2001 and the monthly anomaly values of Z500 and Z300 in every grid point (only the correlation map for Z300 is shown). Fig. 4, in which the spatial correlation between the AIRI and Z300 is displayed, shows that significant positive correlations exist along the subtropical latitudes. A positive AIRI anomaly is associated with positive subtropical geopotential height anomalies in the upper troposphere, which extend westward from the central Asian high region to western coast of Africa and the Atlantic. The respective correlation map between Z500 and AIRI reveals a similar pattern with the one presented in Fig. 4, where a zonal circulation dominates over Eurasia but with slightly weaker correlation coefficients. On the other hand, in the lower troposphere (Z850) the correlation pattern is modified due to the influence of surface systems; the Azores high pressure system in the west and the S.W. Asia thermal low (similar pattern depicted in Fig. 8). The pattern is the same for

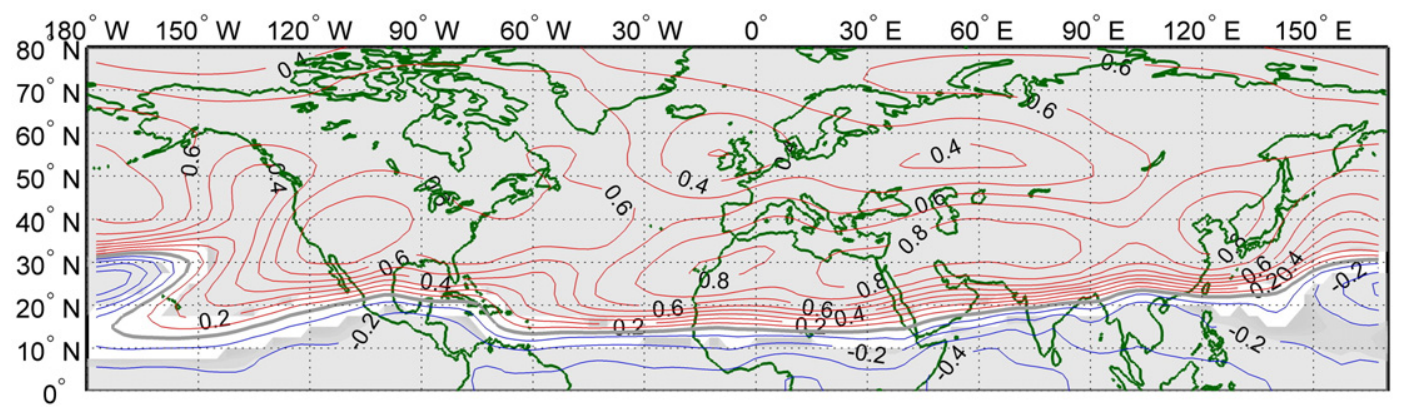

Fig. 4. Correlation map between anomalies of monthly 300 hPa geopotential height and AIRI during the summer period (JJAS) of 1958-2001. Blue contours correspond to negative values, red contours to positive values and thick solid contours to zero. Correlations meeting the $90 \%$ confidence level are shaded. Contour interval is 0.1 . 


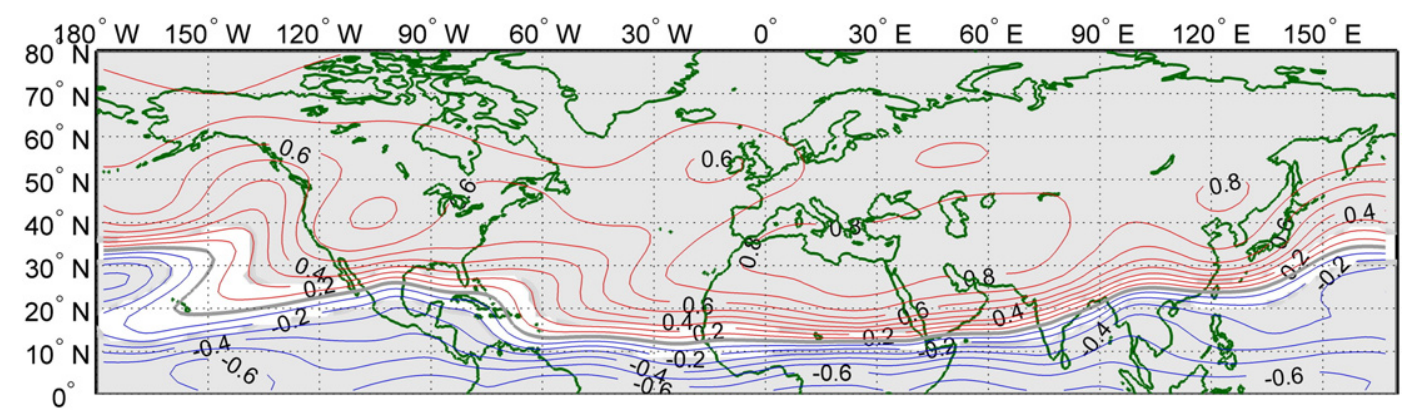

Fig. 5. Correlation map between anomalies of monthly streamfunction values at 0.2101 sigma level and AIRI during the summer period (JJAS) of 1958-2001. Blue contours correspond to negative values, red contours to positive values and thick solid contours to zero. Correlations meeting the $90 \%$ confidence level are shaded. Contour interval is 0.1 .

700 hPa geopotential height and with increased correlation coefficients (by 10-20\%) as compared to the lower level correlation map.

These results are also confirmed by the corresponding correlations between the streamfunction on different sigma levels (0.2582, 0.2101, and 0.1682) and AIRI, which reveal a large anticyclonic gyre extending over the area of interest (Fig. 5; only the correlation map at 0.2101 sigma level is shown, as more representative, for reasons of simplicity). In the middle latitudes significant positive correlation centers are found to exist over west-central Asia and the EM, North Africa, northeastern Asia and North America. This wave pattern looks very similar to the circumglobal pattern observed by Ding and Wang (2005), to the teleconnection pattern investigated by Wang et al. (2001) and the one in Branstator (2002), although the latter is for the winter season. Moreover, the ISM variability is seen to be correlated with the 0.2101 sigma level streamfunction in the extratropical regions as well, though with a weaker correlation when compared to their connection in the subtropical regions.

The warm structure of the troposphere associated with the Rossby wave response to the convective heat source over
India can be seen in the upper level potential temperature $(\theta)$ composites (Fig. 6). Latent heating due to water vapor condensation over the ISM region induces a perturbation/ thermal forcing in the atmosphere. A westward propagation of the thermal signal is a manifestation of the Rossby wave that communicates the information about the heating in the surrounding atmosphere and offers a transition toward a new steady state of the atmosphere, consistent with the appearance of a heat source over the ISM region (Eshel, 2002). Hence, positive $\theta$ anomalies over west-central Asia appear to intensify and spread westward and poleward with height during strong ISM years (Fig. 7a, c). Its maximum lies within the $400-200 \mathrm{hPa}$ layer, where a positive $\theta$ anomaly center is found in the vicinity of the Caspian Sea and a secondary one over EM (Figs. 6, 7b).

\section{ISM and lower level circulation}

Regarding the lower atmosphere, composites of geopotential height anomalies at $850 \mathrm{hPa}$ (Z850) are presented for both weak and strong ISM years in Fig. 8. It can be pointed out that the circulation anomalies present an equivalent barotropic structure throughout the entire troposphere over the tropical, subtropical

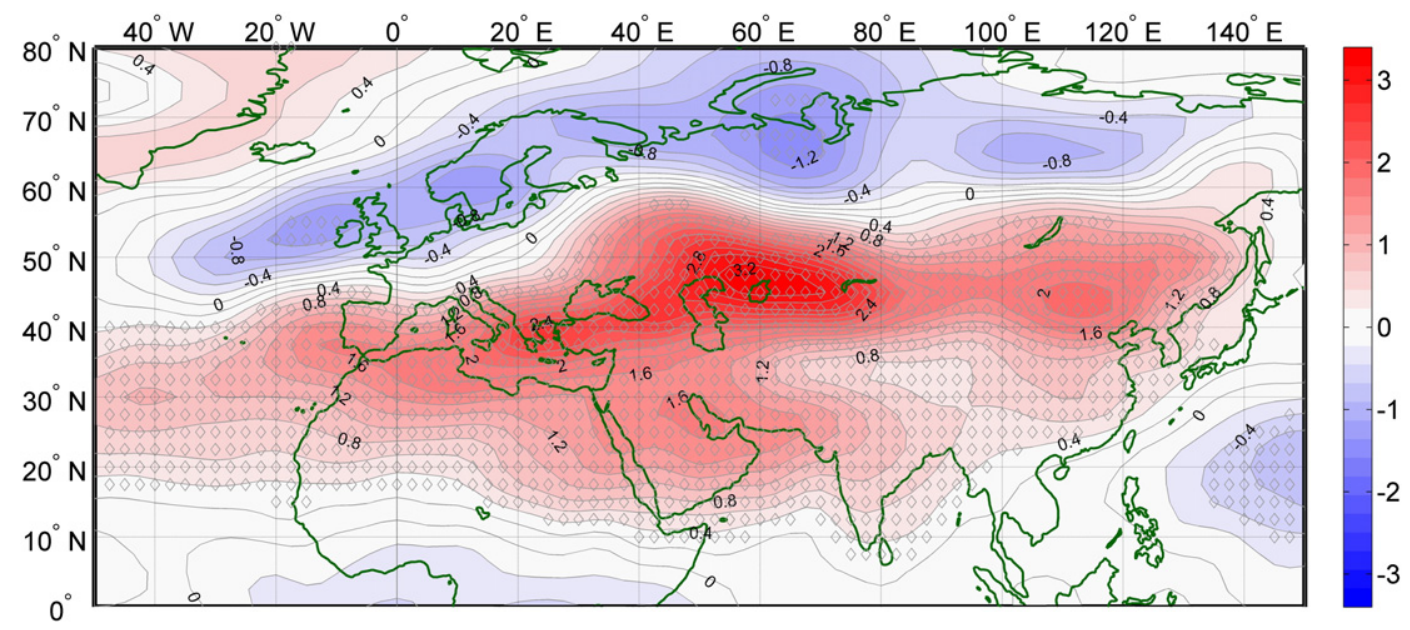

Fig. 6. Composite difference of $\theta$ at $200 \mathrm{hPa}$ (coloured contours with interval of $0.4 \mathrm{~K}$ ) between strong and weak ISM years. Grid points with anomalies that are statistically significant at $90 \%$ confidence level are denoted with diamond symbols. 


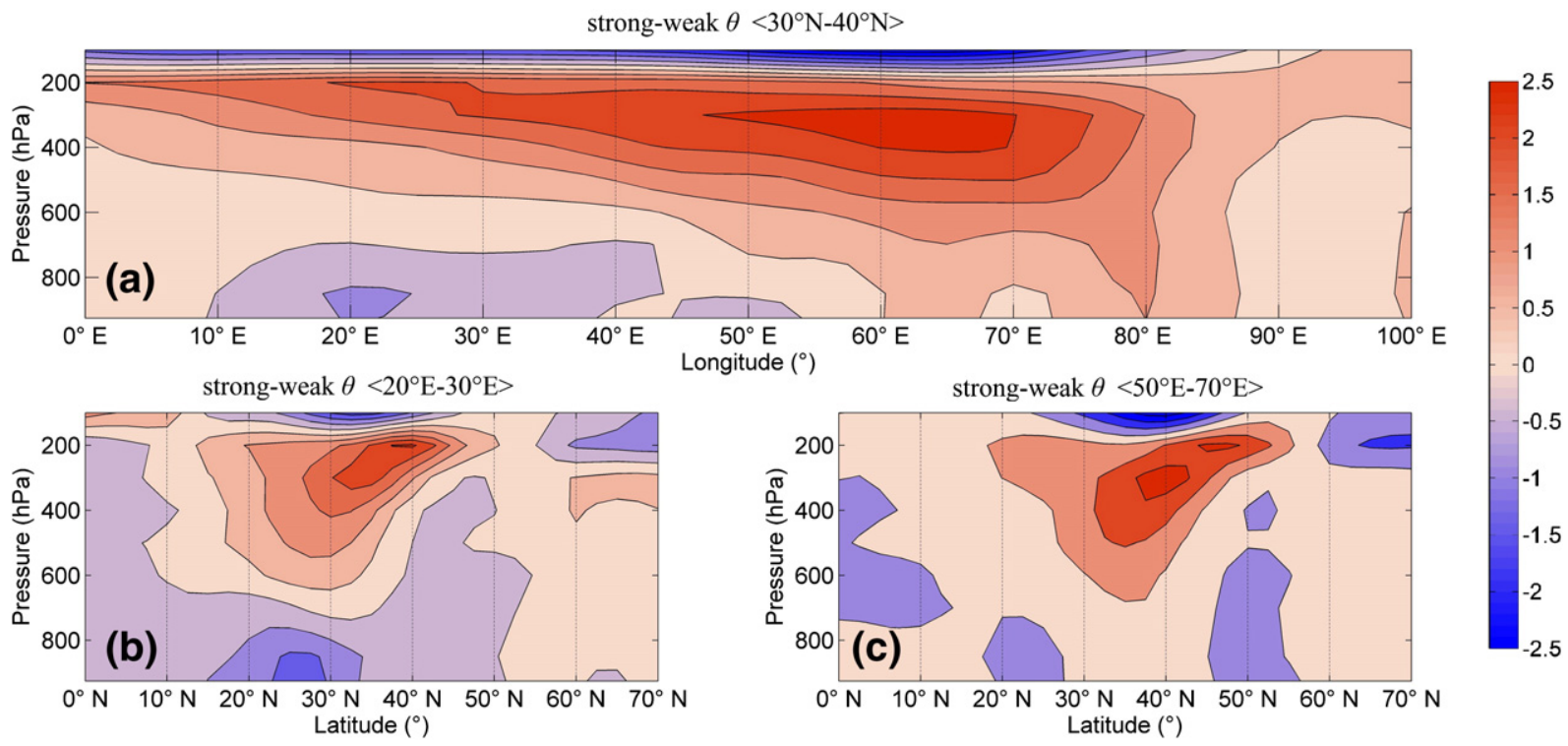

Fig. 7. (a) Longitude-pressure cross-section of the composite differences of $\theta$ (K) between strong and weak ISM years, averaged over the sector $30^{\circ}-40^{\circ} \mathrm{N}$. (b)-(c) Latitude-pressure cross-section of the composite differences of $\theta(\mathrm{K})$ between strong and weak ISM years, averaged over the sector $20^{\circ}-30^{\circ} \mathrm{E}$ (EM region) and over the sector $50^{\circ}-70^{\circ} \mathrm{E}$ (west Asia region) respectively.

and extratropical region from Europe to the North Atlantic. The only exception is the corresponding anomaly center over westcentral Asia, which exhibits a heat-induced baroclinic nature that extends toward EM, suggesting that the diabatic heating related to ISM precipitation plays a crucial role in the development of this circulation pattern over Eurasia. In the Z850 pattern of anomalies for the strong ISM years (Fig. 8a) an intense and extended positive anomaly is located over the north-eastern Atlantic Ocean, extending to western and central Europe and north-west Africa, while negative anomalies extend from the ISM region through the Persian Gulf and further along southern Turkey to the Aegean sea as well as over the region north of the Caspian Sea. According to this pattern, the subtropical anticyclone of the Atlantic (Azores) and the S.W. Asia thermal low appear enhanced during strong ISM years and at the same time the central Europe anticyclone is intensified and expands over the Balkan region and the EM. Greece lies in the middle of two anomaly fields, the central Europe high and the Asian thermal low, over a region of enhanced baroclinicity, where anomalous northeasterly wind currents occur. Consequently, the strengthening of these two systems will have an impact on the Etesian winds as well, which result from the combination of the above mentioned systems (Metaxas and Bartzokas, 1994; Ziv et al., 2004). These results are in agreement with the wind vector anomaly pattern at $850 \mathrm{hPa}$ (see Fig. 8a) for strong ISM years, where an anomalous northerly current is prevalent over eastern and central Mediterranean (Rizou et al., 2012). The anomaly composite related to weak ISM years reveals a similar spatial distribution as in the strong years, though reversed. Accordingly, the wind vector anomalies for the weak ISM years (see Fig. 8b) present an opposite pattern, with anomalous southerlies dominating over EM, corresponding to weakened Etesian winds.

On the other hand, the $500 \mathrm{hPa}$ vertical velocity $(\omega)$ anomaly fields (not shown) depict anomalous subsidence over the EM for the strong ISM years contrasting the anomalous upward motion in the weak ISM years. The correlation map between AIRI and $\omega$ (Fig. 9) shows significant positive correlations over central and eastern Mediterranean, implying subsidence in the area during strong ISM years, which is in accordance with the findings of Ziv et al. (2004). The statistically significant negative correlations over the Indo-Pakistan region and the northern part of the Arabian Sea correspond to enhanced ascending motion during strong ISM years. Weak but significant negative correlations between AIRI and $\omega$ are also found over a large area in the tropics, stretching from tropical Africa until the Bay of Bengal, indicative of the enhanced convection over these areas during strong ISM years.

At the same time, the $2 \mathrm{~m}$ temperature differences between strong and weak ISM years, depicted in Fig. 10a, represent a regime characterized by positive anomalies over central and northern Europe and western Mediterranean and slightly negative values over EM and Middle East countries during strong ISM years. The anomalies mentioned above are found statistically significant over EM at 0.1 significance level. When linearly removing the temperature long-term trend from the ERA40 dataset the anomalies are depicted weakened and are no longer statistically significant. However, Bengtsson et al. (2004) raise the issue of a great uncertainty when calculating trends from the ERA40 dataset used in this study. This could be attributed to changes in observational techniques and coverage over the years, a cold bias emanating from the first guess of the assimilating model and changes in the terrestrial system.

This regime can be related to the influence of the upper level circulation anomaly pattern (see Figs. 1 and 2) and to the 700$1000 \mathrm{hPa}$ thickness pattern, which is presented in Fig. 10b. The 700-1000 hPa thickness pattern indicates a similar structure as the $300 \mathrm{hPa}$ geopotential height anomaly field, with a warm troposphere over the central and northern Europe as well as over western Mediterranean and the area north-west of the ISM region. On the other hand, in EM, from Turkey till north 

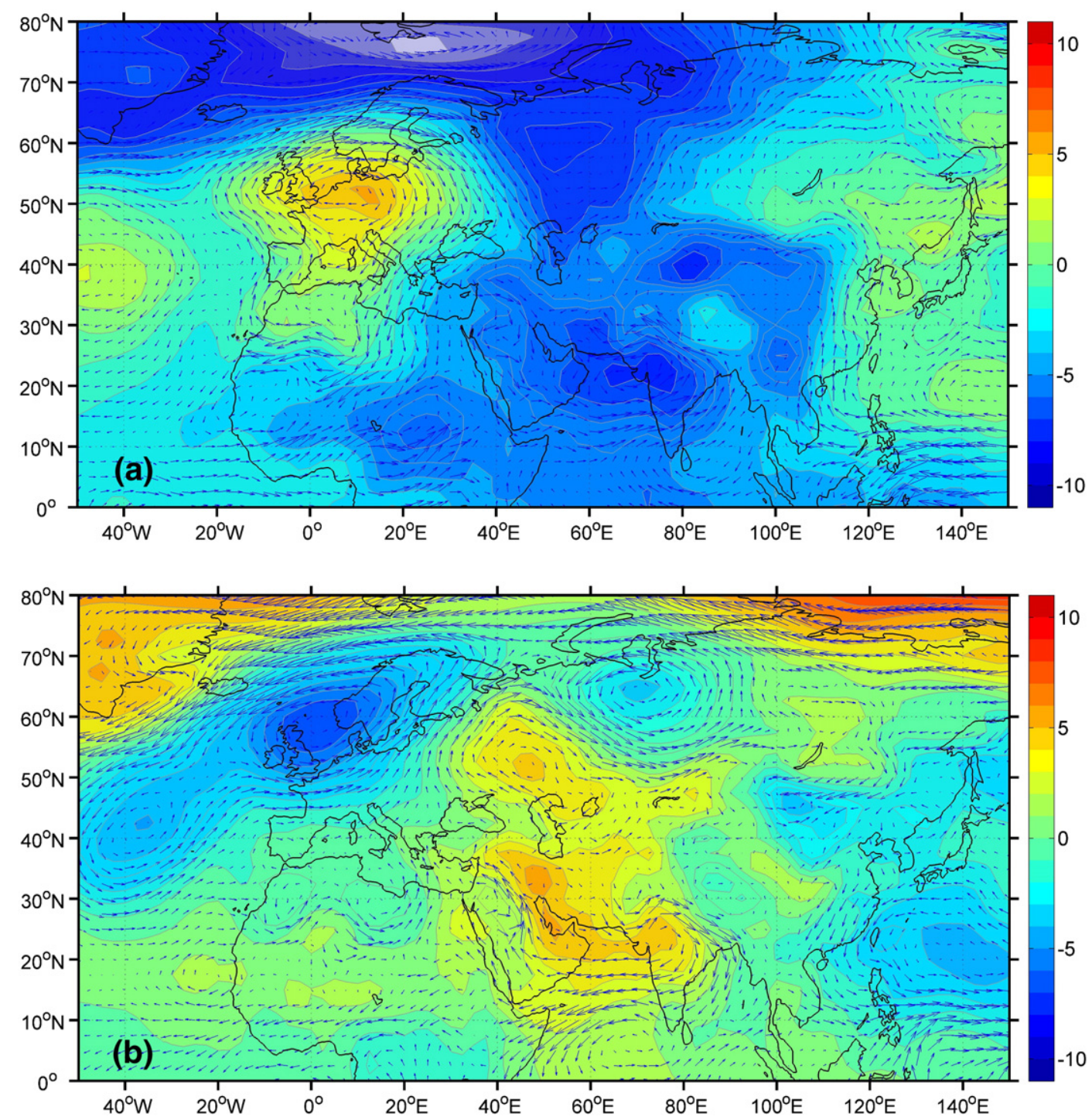

Fig. 8. Seasonal (JJAS) mean anomalies of geopotential height (contour interval of $1 \mathrm{gpm}$ ) and wind vector anomalies at $850 \mathrm{hPa}$ during (a) strong ISM years and (b) weak ISM years. Anomalies are departures from 1958-2001 climatology.

and central Africa, there is significant evidence of a cooler lower troposphere. The pattern is repeated for different thickness fields (500-700 hPa, 500-1000 hPa and 300-500 $\mathrm{hPa}$ ), exhibiting lower anomaly amplitudes over EM and larger amplitudes over central-northern Europe and westcentral Asia within middle and upper troposphere (not shown here). It should be noted that the most significant changes on the thickness of the troposphere over the EM associated with the ISM are identified within the lower part of the troposphere (700-1000 hPa). A cooler lower troposphere over EM can be regarded as a result of the combined action of two primary factors; the mid-tropospheric subsidence and lower-level cool advection, associated with the Etesians (Ziv et al., 2004).

\section{Conclusions}

In this study, the anomalous characteristics of observed large-scale synoptic fields during extreme ISM years are analyzed and compared, as a further attempt to investigate the impact of the ISM on the EM region that has been demonstrated in previous studies. The results indicate that the differences between the anomaly composites in strong and weak ISM years of examined fields are indeed significant, implying that further analysis of the related dynamics is required. Additionally, correlation computations were made in order to reinforce the anomaly composite results and to focus on the linear, in-phase relationship between ISM and circulation parameters over the area.

A strong ISM is clearly associated with an intensification of many atmospheric circulation systems, including the central Asian high, the upper level central-northern Europe high, the East Asian high and the ridge over North America. During strong ISM years these circulation systems appear strengthened Fig. 5, favoring a stronger wave train pattern across Eurasia, Pacific and North America in the lower, mid-, and upper troposphere. In agreement with Tyrlis et al. (2013), a 


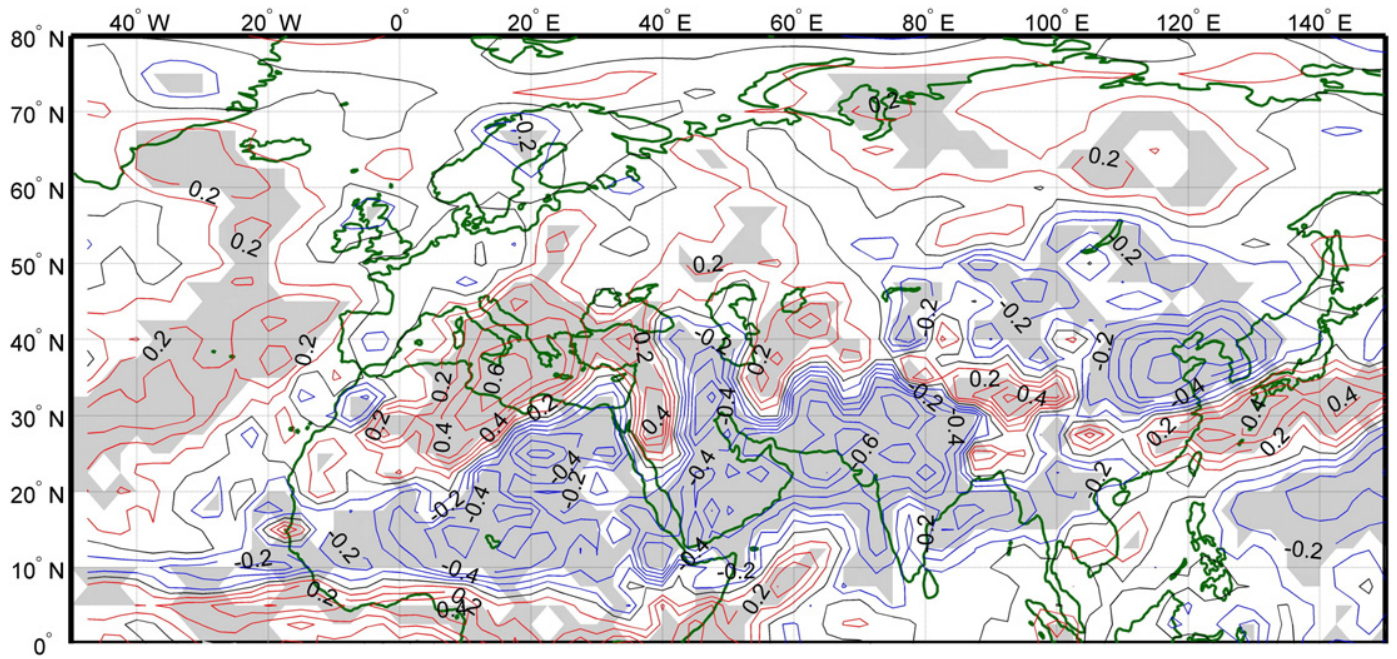

Fig. 9. Correlation maps between anomalies of monthly vertical velocity at $500 \mathrm{hPa}$ and AIRI during the summer period (JJAS) of $1958-2001$. Blue contours correspond to negative values, red contours to positive values and thick solid contours to zero. Correlations meeting the $90 \%$ confidence level are shaded. Contour interval is 0.1 .

stronger than normal ISM was identified to be correlated with a zonally elongated anticyclone along $30^{\circ} \mathrm{N}$ in the upper troposphere, extending westward from Indian Ocean to western coast of Africa and the Atlantic, resembling a Rossby wave response to a tropical heating located near India. Regarding the potential temperature anomalies, a similar pattern was recognized consistent with previous studies (Eshel, 2002; Tyrlis et al., 2013); a strong ISM excites an above normal warming of the troposphere that extends westward from central-west Asia with height and reaches EM area in the $200 \mathrm{hPa}$ layer.

During the strong ISM years the STJ over South Asia is found meridionally shifted poleward, as compared with its climatological mean position, expanding enhanced over EM. On the contrary, it was found that the weak ISM years are linked with the equatorward shift of the STJ over South Asia and a weakening of its intensity over EM. On the other hand, the meridional wind anomaly pattern at $300 \mathrm{hPa}$ in the strong ISM years revealed a well-organized Rossby wave train, expanding over Eurasia and connecting ISM region with EM. In the weak ISM years, the anomaly composite of $300 \mathrm{hPa}$ meridional wind was completely different, unorganized anomalies with no specific orientation. These results suggest a strong relation between well-organized Rossby wave trains over Eurasia and the intensity of ISM, as Rodwell and Hoskins (1996) have also described. However, this issue requires further investigation with the aid of model simulations in order to clarify the nature of the relation between the ISM and the Rossby waves that are observed propagating over the monsoon area up to the North Atlantic region.

Ramaswamy (1962) stated that the position of the STJ has an impact on the ISM development while the related position of the STJ and ETJ over the monsoon region has been proved to play a role in the intraseasonal variability of the ISM. In this study, a significant interannual correlation between the anomalies of the two jets was found, revealing the significance of the position and intensity of both jets in the ISM variability.
Finally, the geopotential height anomaly patterns in the lower atmosphere for the extreme ISM years indicated the intensification of the central Europe anticyclone and the thermal Asian low in the strong ISM years and the respective decay of both systems in the weak ISM years. As a result, enhanced northerlies appear to be dominating over EM in the strong ISM years, as concluded from the $850 \mathrm{hPa}$ meridional wind anomalies, with an impact on the temperature regime of the region (Rizou et al., 2012). Enhanced subsidence over the EM, which appears synchronously with enhanced ascend over the Indo-Pakistan region, induces adiabatic warming counteracting the cool advection due to these anomalous northerly winds (Etesians). Near surface temperature and thickness anomalies revealed warmer than normal conditions over central-north Europe and western Mediterranean and evidence of cooler conditions within the lower troposphere over EM and northeastern-central Africa. These results agree with the findings of Ziv et al. (2004), based on a single summer season, demonstrating that the temperature regime over the EM is dominated by the ISM, resulting in a weak interdiurnal temperature variation over the EM. However, Harpaz et al. (2014) showed that except for the ISM, midlatitude disturbances and tropical intrusions can also influence the evolution of extreme temperature events over the EM.

The mechanism of the teleconnection between EM and ISM will be the subject of a further study, with the aid of model simulations and the investigation of the related dynamics. In addition, the inter-relation between the climatic regimes of EM and SW Asia in an intraseasonal time scale is yet to be addressed and especially the connection between the ISM and the Etesian pattern regime over EM.

\section{Acknowledgments}

This research has been co-financed by the European Union (European Social Fund-ESF) and Greek national funds through the Operational Program "Education and Lifelong Learning" of 

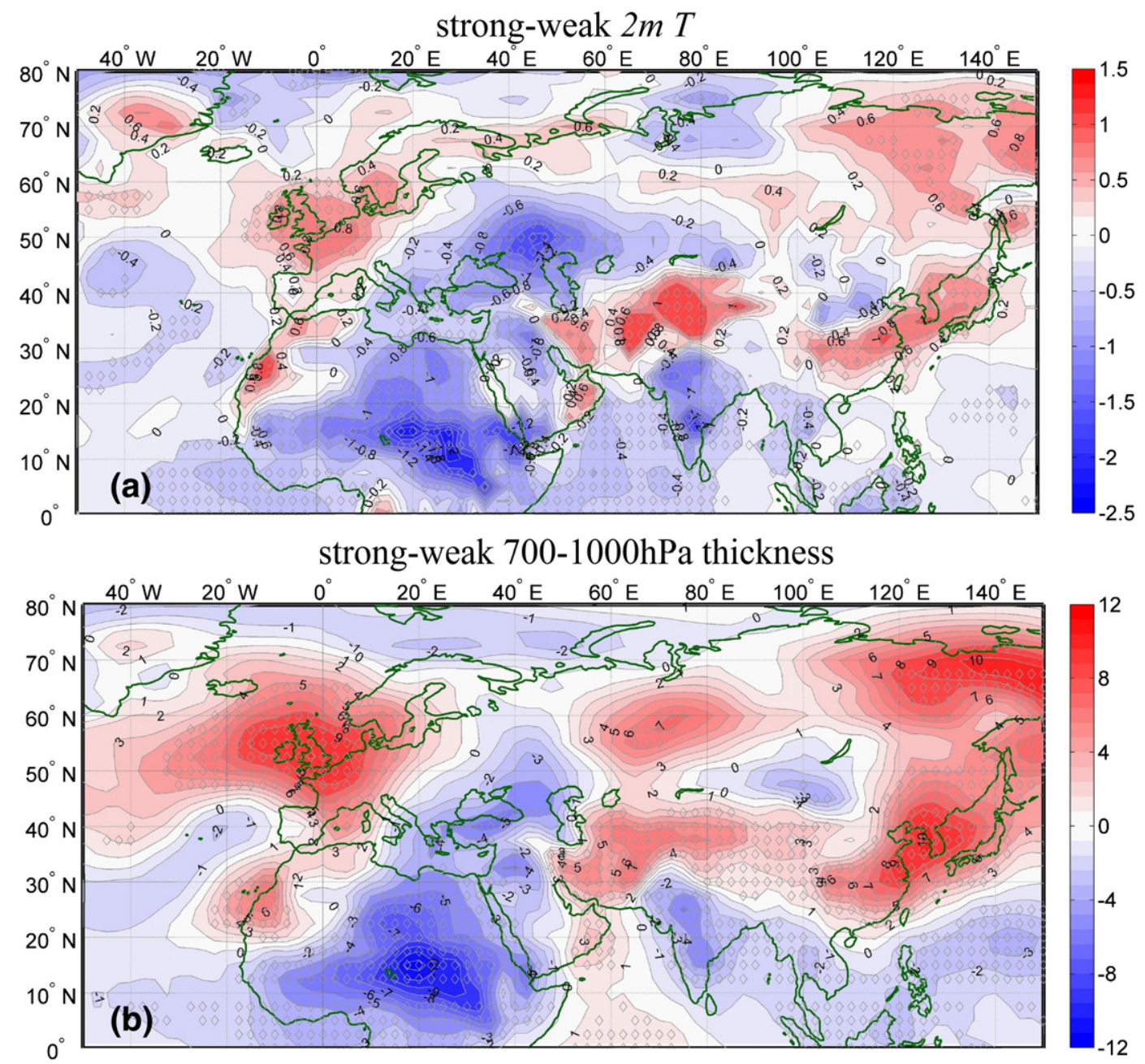

Fig. 10. Composite difference of (a) $2 \mathrm{~m}$ temperature (coloured contours with interval of $0.2^{\circ} \mathrm{C}$ ) and (b) $700-1000$ hPa thickness (coloured contours with interval of $1 \mathrm{gpm}$ ) between strong and weak ISM years. Diamond symbols indicate statistical significance at $90 \%$ confidence level.

the National Strategic Reference Framework (NSRF)-Research Funding Program: Heracleitus II. Investing in knowledge society through the European Social Fund.

\section{References}

Arseni-Papadimitriou, A., Maheras, P.,Giles, B., 1988. Contribution to the study of the strong north winds on Aegean Sea in warm season. Riv. Meteorol. Aeronaut. 48 (3-4), 131-137.

Baldi, M.,Dalu, G.,Maracchi, G.,Pasqui, M.,Cesarone, F., 2006. Heat waves in the Mediterranean: a local feature or a larger-scale effect? Int. J. Climatol. 26, 1477-1487.

Bengtsson, L.,Hagemann, S.,Hodges, K.I., 2004. Can climate trends be calculated from reanalysis data? J. Geophys. Res. 109, D11111.

Branstator, G., 2002. Circumglobal teleconnections, the jet stream waveguide, and the North Atlantic Oscillation. J. Clim. 15, 1893-1910.

Brikas, D.P., Karacostas, T.S., Pennas, P.J., Flocas, A.A., 2006. The role of the subtropical jet stream during heat wave events over north-central Greece. Meteorog. Atmos. Phys. 94, 219-233.

Cassou, C., Terray, L.,Phillips, A.S., 2005. Tropical Atlantic influence on European heat waves. J. Clim. 18, 2805-2811.

Ding, Y.H., Sikka, D.R., 2005. Synoptic systems and weather in the Asian monsoon. In: Wang, B. (Ed.), The Asian Monsoon. Springer, Praxis, pp. 131-201.
Ding, Q.,Wang, B., 2005. Circumglobal teleconnection in the Northern Hemisphere summer. J. Clim. 18, 3483-3505.

Ding, Q., Wang, B., 2007. Intraseasonal teleconnection between the Eurasian wave train and Indian summer monsoon. J. Clim. 20, 3751-3767.

Ding, Q.,Wang, B.,Wallace, J.M.,Branstator, G., 2011. Tropical-extratropical teleconnections in boreal summer: observed interannual variability. J. Clim. $24,1878-1896$.

El Kenawy, A., López-Moreno, J.I., Vicente-Serrano, S.M., 2012. Trend and variability of surface air temperature in northeastern Spain (1920-2006): linkage to atmospheric circulation. Atmos. Res. 106, 159-180.

Eshel, G., 2002. Mediterranean climates. Israel J. Earth Sci. 51, 157-168.

Fontaine, B.,Monerie, P.,Gaetani, M.,Roucou, P., 2011. Climate adjustments over the African-Indian monsoon regions accompanying Mediterranean Sea thermal variability. J. Geophys. Res. 116, D23.

Fujinami, H., Yasunari, T., 2004. Submonthly variability of convection and circulation over and around the Tibetan Plateau during the boreal summer. J. Meteorol. Soc. Jpn 82, 1545-1564.

Gaetani, M., Baldi, M., Dalu, G.A., Maracchi, G., 2011. Jetstream and rainfall distribution in the Mediterranean region. Nat. Hazards Earth Syst. 11, $1-14$

García-Serrano, J., Polo, I., Rodríguez-Fonseca, B., Losada, T., 2013. Largescale atmospheric response to eastern Mediterranean summer-autumn SST anomalies and the associated regional impact. Clim. Dyn. 41 (9-10), 2251-2265.

Harpaz, T.,Ziv, B., Saaroni, H., Beja, E., 2014. Extreme summer temperatures in the East Mediterranean - Dynamical analysis. Int. J. Clim. 34 (3), 849-862. 
Hoskins, B.J., Ambrizzi, T., 1993. Rossby wave propagation on a realistic longitudinally varying flow. J. Atmos. Sci. 50, 1661-1671.

Kalnay, et al., 1996. The NCEP/NCAR 40-year reanalysis project. Bull. Am. Meteorol. Soc. 77, 437-470.

Kripalani, R.H., Kulkarni, A., 1997. Rainfall variability over southeast Asiaconnections with Indian monsoon and ENSO extremes: new perspective. Int. J. Climatol. 17, 1155-1168.

Kripalani, R.H.,Kulkarni, A., 2001. Monsoon rainfall variations and teleconnections over south and east Asia. Int. J. Climatol. 21, 603-616.

Kripalani, R.H., Singh, S.V., 1993. Large-scale aspects of India-China summer monsoon rainfall. Adv. Atmos. Sci. 10, 72-84.

Lin, H., 2009. Global extratropical response to diabatic heating variability of the Asian summer monsoon. J. Atmos. Sci. 66, 2697-2713.

Lin, H., Derome, J., Brunet, G., 2007. The nonlinear transient atmospheric response to tropical forcing. J. Clim. 20, 5642-5665.

Metaxas, D.A., Bartzokas, A., 1994. Pressure covariability over the Atlantic, Europe and N. Africa. Application: centers of action for temperature, winter precipitation and summer winds in Athens, Greece. Theor. Appl. Climatol. 49, 9-18.

Pai, D.S., Rajeevan, M., 2007. Indian monsoon onset: variability and prediction. NCC Research Report No 6. India Meteorological Department, Pune, India.

Parthasarathy, B., Munot, A.A., Kothawale, D.R., 1994. All India monthly and seasonal rainfall series 1871-1993. Theor. Appl. Climatol. 49, 217-224.

Parthasarathy, B., Munot, A.A., Kothawale, D.R., 1995. Monthly and Seasonal Rainfall Series for All-India Homogeneous Regions and Meteorological Subdivisions. Indian Inst. of Trop. Meteorol, Pune, India, pp. 1871-1994.

Pattanaik, D.R., Satyan, V., 2000. Fluctuations of Tropical Easterly Jet during contrasting monsoons over India: A GCM study. Meteorol. Atmos. Phys. 75, 51-60.

Paz, S., Tourre, Y., Planton, S., 2003. North Africa-west Asia (NAWA) sea-level pressure patterns and its linkages with the eastern Mediterranean (EM) climate. Geophys. Res. Lett. 30 (19), 1999-2002.

Paz, S., Tourre, Y.M.,Brolley, J., 2008. Multi-temporal climate variability over the Atlantic ocean and Eurasia: linkages with Mediterranean and west African climate. Atmos. Sci. Lett. 9, 196-201.

Prezerakos, N.G., Flocas, H.A., 2002. Regional and global large-scale dynamics associated with a prolonged drought event in Greece. J. Atmos. Sol-Terr. Phys. 64, 1841-1854.

Raicich, F., Pinardi, N., Navarra, A., 2003. Teleconnections between Indian Monsoon and Sahel rainfall and the Mediterranean. Int. J. Climatol. 23, 173-186.
Ramaswamy, C. 1962. Breaks in the Indian summer monsoon as a phenomenon of interaction between the easterly and the subtropical westerly jet streams. Tellus 14A, 337-349.

Rizou, D.,Flocas, H.A.,Athanasiadis, P.,Bartzokas, A., 2012. Large-scale variability over Mediterranean associated with the Indian summer monsoon. Adv. Meteorol. Climatol. Atmos. Phys. http://dx.doi.org/10.1007/978-3-64229172-2_99.

Rodwell, M.J.,Hoskins, B.H., 1996. Monsoon and the dynamics of deserts. Q. J. R. Meteorol. Soc. 122, 1385-1404.

Rodwell, M.J., Hoskins, B.J., 2001. Subtropical anticyclones and summer monsoons. J. Clim. 14, 3192-3211.

Tourre, Y., Paz, S., 2004. The North-Africa/Western Asia (NAWA) sea level pressure index: a Mediterranean signature of the northern annular mode (NAM). Geophys. Res. Lett. 31, L17209.

Tyrlis, E., Lelieveld, J., Steil, B., 2013. The summer circulation over the eastern Mediterranean and the Middle East: influence of the South Asian monsoon. Clim. Dyn. 40 (5-6), 1103-1123.

Uppala, et al., 2005. The ERA-40 re-analysis. Q. J. R. Meteorol. Soc. 131, 2961-3012.

Wang, B., Fan, Z., 1999. Choice of South Asian summer monsoon indices. Bull. Am. Meteorol. Soc. 80, 629-638.

Wang, B.,Wu, R.G.,Lau, K.M., 2001. Interannual variability of the Asian summer monsoon: contrasts between the Indian and the western North PacificEast Asian monsoons. J. Clim. 14, 4073-4090.

Wu, Z.W.,Jiang, Z.,He, J., 2006. The comparison analysis of flood and droughts features among the first flood period in South China, Meiyu period in the Yangtze River and Huaihe River valleys and rainy season in north China in the late 50 years (in Chinese). J. Atmos. Sci. 30 (3), 391-401.

Wu, Z.W.,Wang, B., Li, J.,Jin, F.F., 2009. An empirical seasonal prediction model of the East Asian summer monsoon using ENSO and NAO. J. Geophys. Res. 114, D18120.

Yin, M.T., 1949. A synoptic-aerologic study of the onset of the summer monsoon over India and Burma. J. Meteorol. 6, 393-400.

Zhao, P., Zhang, X., Li, Y., Chen, J., 2009. Remotely modulated tropical-North Pacific ocean-atmosphere interactions by the South Asian high. Atmos. Res. 94 (1), 45-60.

Ziv, B.,Saaroni, H.,Alpert, P., 2004. The factors governing the summer regime of the eastern Mediterranean. Int. J. Climatol. 24, 1859-1871. 